\title{
Design, Activation, and Operation of the J2-X Subscale Simulator (JSS)
}

\author{
G.P. Saunders ${ }^{1}$ \\ Jacobs Technology, Tullahoma, TN, 37388 \\ and \\ N.G. Raines ${ }^{2}$ and D.G. Varner ${ }^{3}$ \\ National Aeronautics and Space Administration, Stennis Space Center, MS, 39529
}

\begin{abstract}
The purpose of this paper is to give a detailed description of the design, activation, and operation of the J2-X Subscale Simulator (JSS) installed in Cell 1 of the E3 test facility at Stennis Space Center, MS (SSC). The primary purpose of the JSS is to simulate the installation of the J2-X engine in the A3 Subscale Rocket Altitude Test Facility at SSC. The JSS is designed to give aerodynamically and thermodynamically similar plume properties as the J2-X engine currently under development for use as the upper stage engine on the ARES I and ARES V spacecraft. The JSS is a scale pressure fed, LOX/GH fueled rocket that is geometrically similar to the J2-X from the throat to the nozzle exit plane (NEP) and is operated at the same oxidizer to fuel ratios and chamber pressures. This paper describes the heritage hardware used as the basis of the JSS design, the newly designed rocket hardware, igniter systems used, and the activation and operation of the JSS.
\end{abstract}

\section{Nomenclature}

SSC = Stennis Space Center, MS

$S D T \quad=$ Subscale Diffuser Test Project

$E 3 C 1=$ Refers to test cell 1 at test facility E3 at the E-complex at SSC

$E 3 C 2=$ Refers to test cell 2 at test facility E3 at the E-complex at SSC

$\mathrm{LH}=$ Liquid Hydrogen

LOX = Liquid Oxygen

GH $\quad=$ Gaseous Hydrogen

JSS $\quad$ J2-X Subscale Simulator

\section{Introduction}

$\mathrm{T}$

HIS document provides a description of the design, activation, and operation of the J2-X Subscale Simulator (JSS) installed in Cell 1 of the E3 test facility at Stennis Space Center, MS (SSC). The JSS is designed to give aerodynamic and thermodynamic plume properties similar to the J2-X engine currently under development for use as the upper stage engine on the ARES I and ARES V spacecraft. The JSS is a scale pressure fed, LOX/GH fueled rocket that is geometrically similar to the $\mathrm{J} 2-\mathrm{X}$ from the throat to the nozzle exit plane (NEP) and is operated at the same oxidizer to fuel ratios and chamber pressures. The A3 Subscale Diffuser (SDT) project requires the use of the JSS to verify aerodynamic performance of the A3 facility rocket diffuser and to obtain experimental data quantifying the heat flux throughout the facility. Background information regarding the project objectives of the SDT project are outlined in Reference 1.

The rocket hardware used as the foundation of the JSS design is the DTF rocket (see Figure 1). The DTF (Diagnostic Test Facility) rocket was used in the late 1980's at SSC for plume diagnostic studies. The DTF rocket is

1 Fluid Dynamics Laboratory Manager Advanced Technology Segment, 600 William Northern Blvd., Tullahoma, TN, 37388, Member.

2 Mechanical Engineer, Engineering and Science Directorate, Building 3225, SSC, MS 39529.

${ }^{3}$ Systems Engineer, Engineering and Science Directorate, Building 3225, SSC, MS 39529.

American Institute of Aeronautics and Astronautics 092407 
a pressure fed LOX/GH rocket with multiple co-axial (LOX post) injectors, capable of producing approximately $1000 \mathrm{lbf}$ of thrust. The DTF rocket engine itself is an incarnation of the $1.2 \mathrm{~K}$ Thrust Rocket Engine originally developed at Marshall Space Flight Center (MSFC) in 1964. Multiple versions have used at MSFC over the years for fuel injector and nozzle material development and plume diagnostic projects. Another version was used at Arnold Engineering Development Center (AEDC) in the 1970s.

\section{Design}

The DTF rocket includes a stainless steel injector assembly (Figure 2), a stainless steel outer pressure casing, and a copper combustion chamber/nozzle liner. The DTF chamber liner is a one piece copper liner with an integral nozzle. Cooling water is routed between the chamber liner and pressure casing opposite the direction of the hot combustion chamber gases. A port is provided in the center of the injector for the admittance of an ignition source. Access to the port is provided through what is referred to as the TEA pin (Figure 2), so called because the original MSFC design in the 1960s used triethylaluminum (TEA) injection as the ignition source. The TEA pin contains a thru hole along its centerline and annular groove on its circumference. The original 1.2K MSFC engine injected the TEA via the annular grooves which provide swirl to the TEA flow to enhance ignition. Combustion chamber measurement was made through the center thru-hole port. The DTF rocket reversed the process. The DTF rocket used the hot exhaust gases of an Estes model solid rocket motor as the ignition source. In this configuration, the expelled Estes rocket combustion gases were discharged the center port, while combustion chamber pressure was measured through the annular grooves.

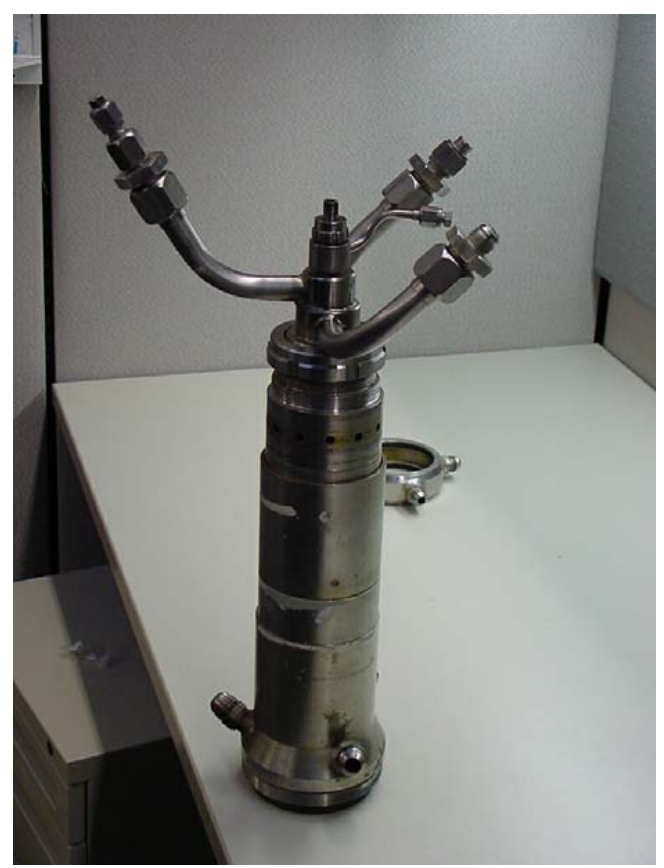

Figure 1. DTF Rocket Motor
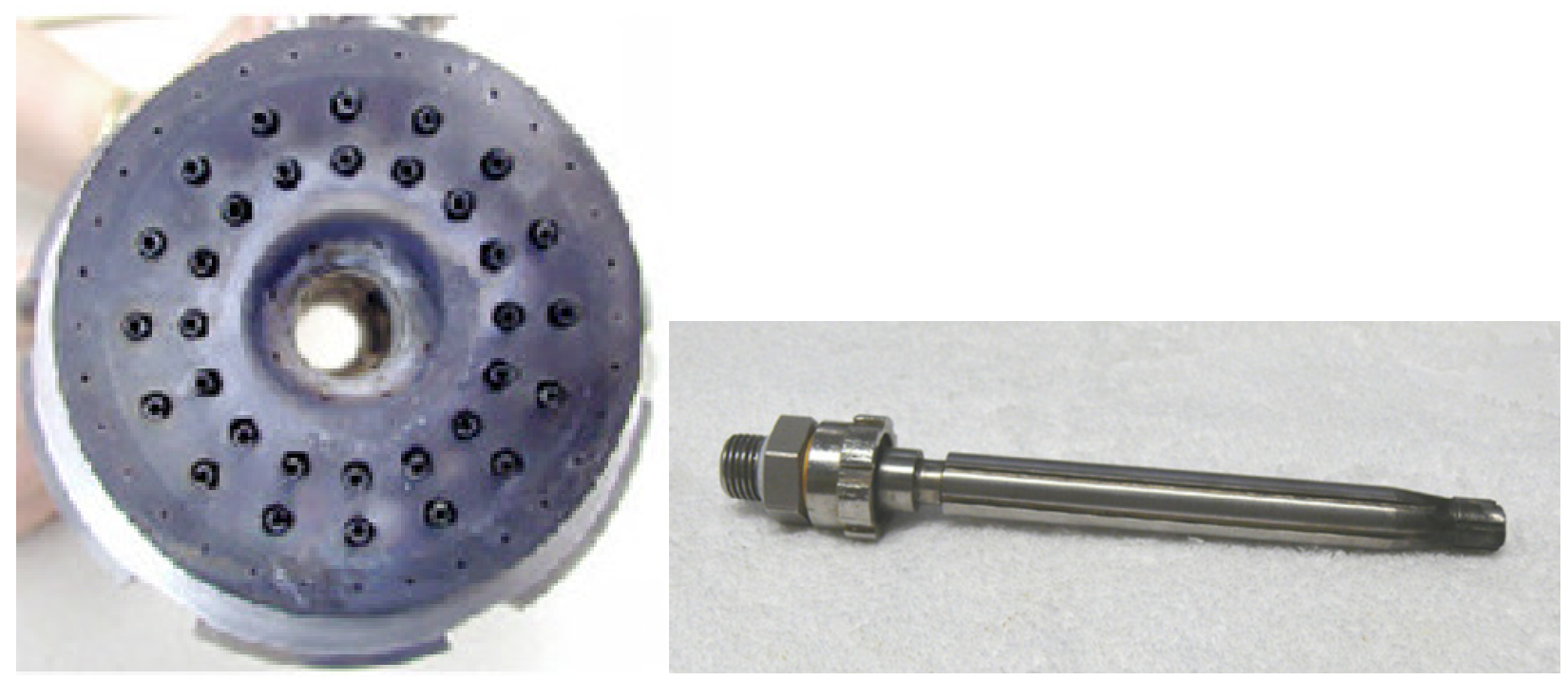

Figure 2. Injector and TEA Pin 


\section{A. JSS Rocket}

The J2-X simulator (JSS) is required to operate at two conditions to simulate the $\mathrm{J} 2-\mathrm{X}$; 100\% rocket power level (RPL) and 80\% RPL. Previous experience with the DTF rocket was at higher flow rates and at lower chamber pressures than required of the JSS. It was expected that the elevated chamber pressure and reduced mass flow required by the JSS would tend to push the combustion region in the chamber closer to the injector face than had been previously experienced. Therefore there was some concern that the JSS would experience heating problems at the injector face. To mitigate this risk, an existing spare injector was modified to include materials for the LOX posts and faceplate designed for high temperature resistance.

The JSS combustion chamber liner design is very similar to the DTF (see Figure 3). The new liner was designed such the combustion chamber end of the liner is essentially identical to the DTF liner to fit the existing fuel injector and pressure casing hardware. The nozzle contour was designed to match the potential flow contour of the J2-X engine starting at the nozzle throat at the subscale facility's scale. The existing DTF hardware limits the nozzle area ratio of the water cooled copper liner. Therefore a nozzle extension is required to extend the nozzle out to the required area ratio.

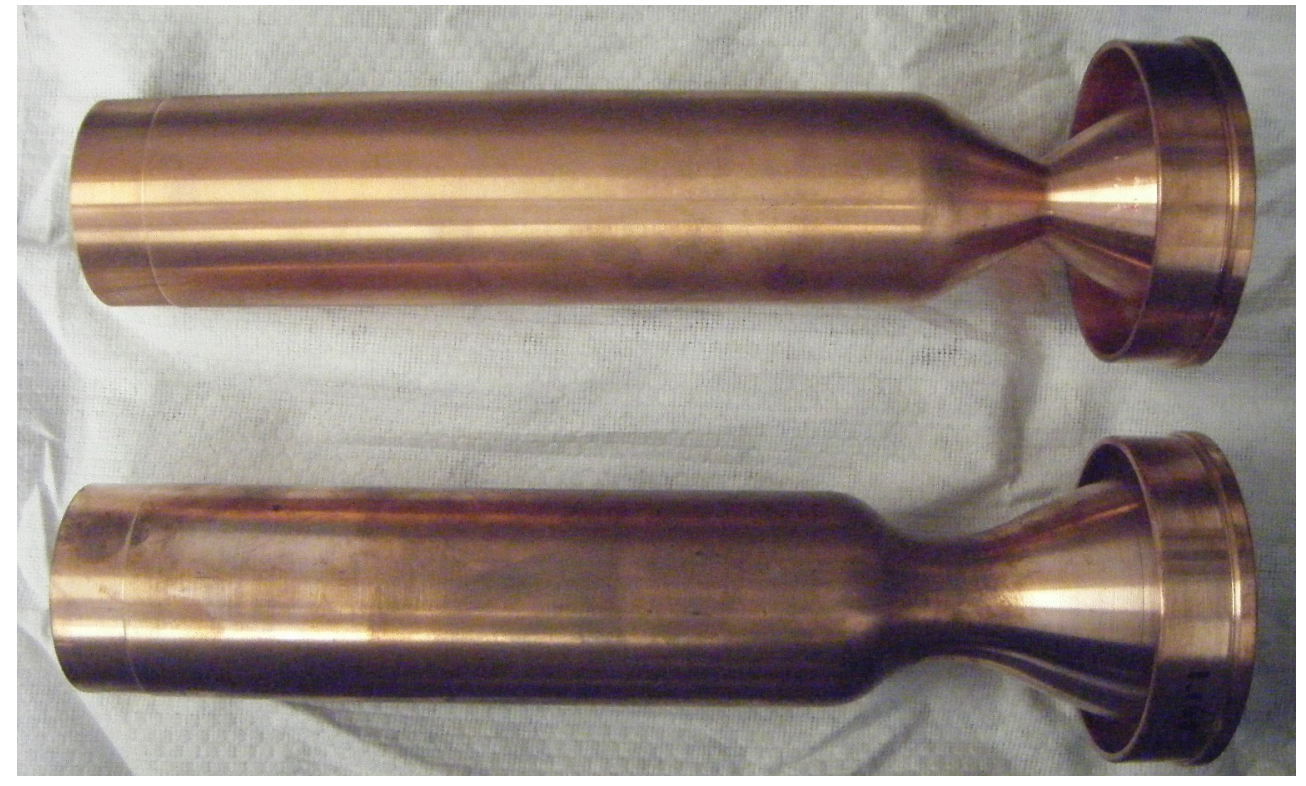

Figure 3. JSS Liner (Top) and DTF Liner (Bottom)

The camber liner is held in place in the pressure casing by a brass baffle with the similar but offset contour. In addition to locating the chamber liner in the pressure casing, the baffle also provides a means to direct cooling water to the nozzle throat. Water is prevented from flowing around the outside of the baffle by an o-ring. A constant water passage height must be maintained around the outside surface of the liner. The original baffle design incorporated steel wire to maintain the passage height. The second version used brass wire to ease installation and reduce cooling water system pressure losses. The final incarnation uses brass keys machined to match the exterior contour of the chamber liner to further ease installation and eliminate wire failure which will be discussed later in this paper. The brass keyed chamber baffle is shown in Figure 4.

A threaded flange was built that mounts onto the outside diameter at the aft end of the pressure casing. This allows the attachment of the nozzle extension. The nozzle extension extends the nozzle area ratio from the chamber liner limit to the area ratio required at the nozzle exit plane. It was 
determined that the static temperature was low enough throughout the nozzle extension and maximum test duration short enough to allow the nozzle extension to be un-cooled. The nozzle extension has blind tapped holes on the upstream face to allow attachment to the threaded flange described above on the JSS. The extension contour has a tapered locating groove on the inlet side to ensure proper alignment with minimal flow disturbance at the liner/extension interface. The nozzle extension/liner interface also utilizes a red silicon o-ring to eliminate communication between the inside of the nozzle and the test cell atmosphere. When built, it was unknown what potential truncated nozzle are ratio would be required for future test objectives. Therefore four full nozzle extensions were built with the intention of simply saw cutting the extensions to the required area ratio. Since then, two of the nozzles have been cut to other area ratios and an additional nozzle extension with a constant wall thickness was built and instrumented with high response pressure transducers to measure the nozzle differential pressure during facility shutdown. The instrumented nozzle was used during steam generation tests only. The JSS was never hot fired with the instrumented nozzle installed. Photos of the original nozzle extensions and the instrumented nozzle extension are shown in Figure 5. A section view of the JSS assembly and a JSS installed in the subscale test cell are shown in Figures 6 and 7 respectively.

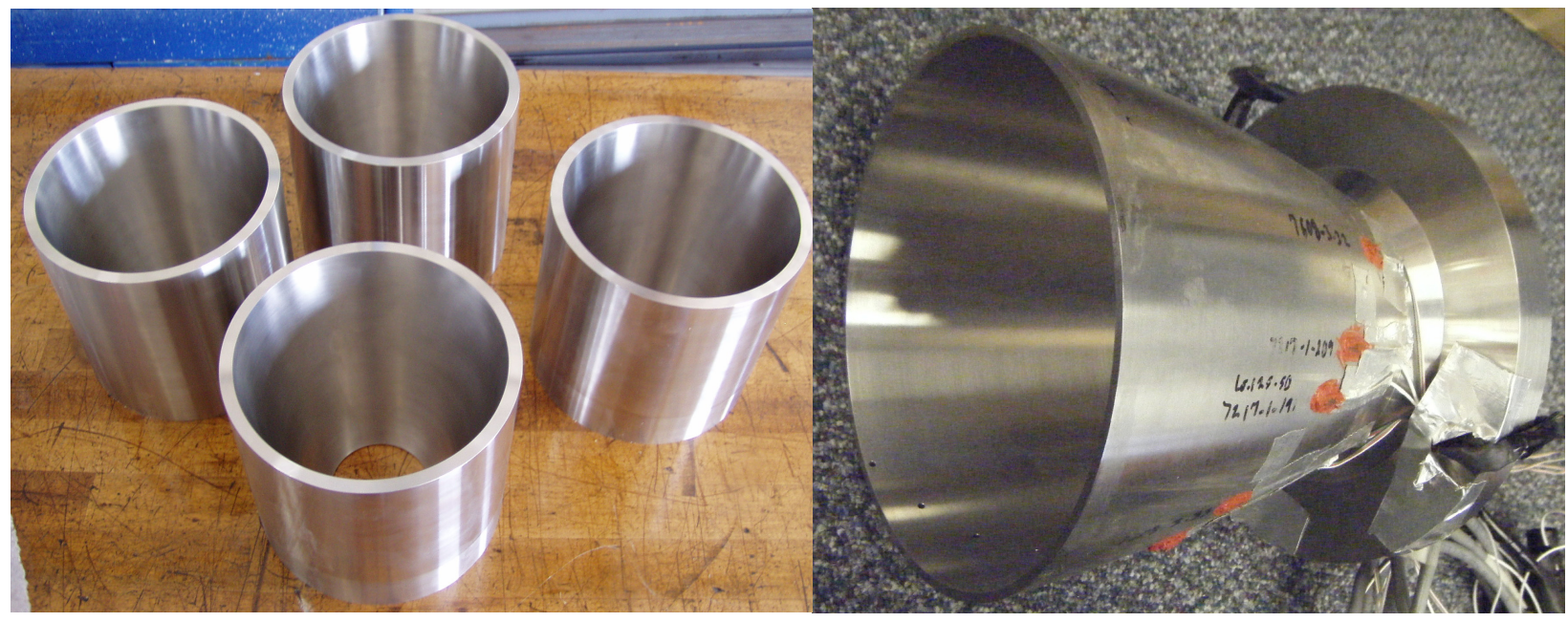

Figure 5. Hot Fire Nozzle Extensions (Left) and Instrumented Nozzle Extension (Right)

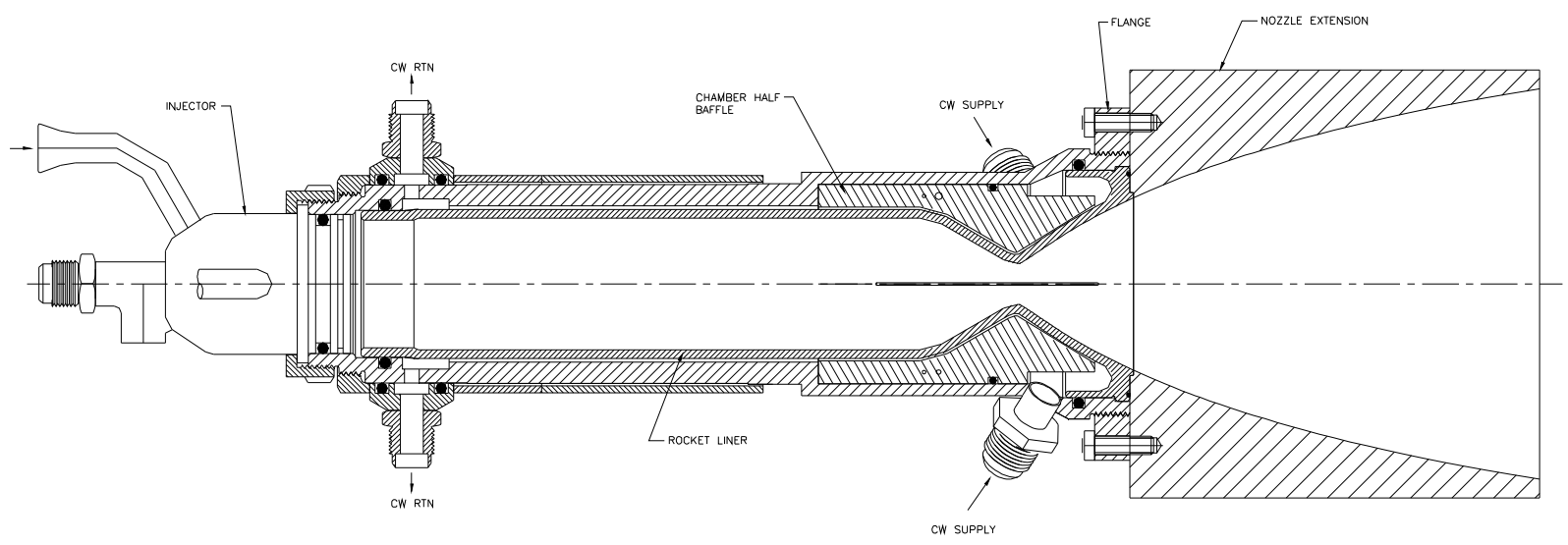

Figure 6. Section View of JSS Assembly 


\section{B. Igniters}

JSS activation and early test firings utilized an Estes model solid rocket motor (Figure 8) similar to the one used with the DTF rocket to initiate combustion. Existing canisters from the DTF program were used to hold the Estes rockets in place and interface with the TEA pin. This approach was initially favored because there was existing hardware available and there was prior experience at SSC using the Estes rocket motors. The use of the Estes rockets, however, required the canisters to be reloaded between every test firing with a fresh motor and did not allow restart of the JSS during steam generation (maximum run time of the JSS is 6 seconds while maximum steam generation duration is 180 seconds). Also, the Estes motors did not prove as reliable as desired. This was a safety concern because the Estes motor hot fire duration was so short that the JSS main oxidizer and fuel prevalves were required to open prior to ignition of the Estes motor to ensure that a combustible mixture was realized in the combustion chamber simultaneously with the hot gases expelled from the Estes motor. Therefore, if an Estes misfire occurred, both unburned oxidizer and fuel would be admitted through the JSS engine and into subscale diffuser.

It was desired to have the ability the relight the JSS multiple times during steam generation and to be able to detect igniter combustion prior to opening the oxidizer and fuel prevalves, and thus to advance to facility shutdown if igniter combustion did not occur. Therefore a GOX/GH spark igniter was designed. The initial spark igniter design was a slightly modified version of a $\mathrm{GOX} / \mathrm{CH}_{4}$ igniter used previously at SSC. The igniter used a low oxidizer-to-fuel mixture ratio to maintain the igniter chamber temperature low enough to allow the use of an un-cooled igniter housing. Also, a port was added to allow the insertion of a high response coaxial thermocouple to allow rapid detection of ignition. All fuel and oxidizer ports were left as designed for the $\mathrm{GOX} / \mathrm{CH}_{4}$ igniter. Use of the existing design did not produce good oxidizer-fuel mixing and the oxidizer entry port proved to be too close to the spark plug electrode. Failure of the original GOX/GH spark igniter is discussed later in this paper.

The GOX/GH spark igniter was redesigned to move the fuel and oxidizer inlet ports farther away from the spark plug tip and also arranged the ports to create an impinging triplet where two fuel ports were directed just aft of the oxidizer inlet port to enhance mixing in the igniter chamber. Figure 9 shows a section of the original and redesigned GOX/GH spark igniter showing the inlet port orientation. A photograph of the redesigned spark igniter currently in use is shown in Figure 10.

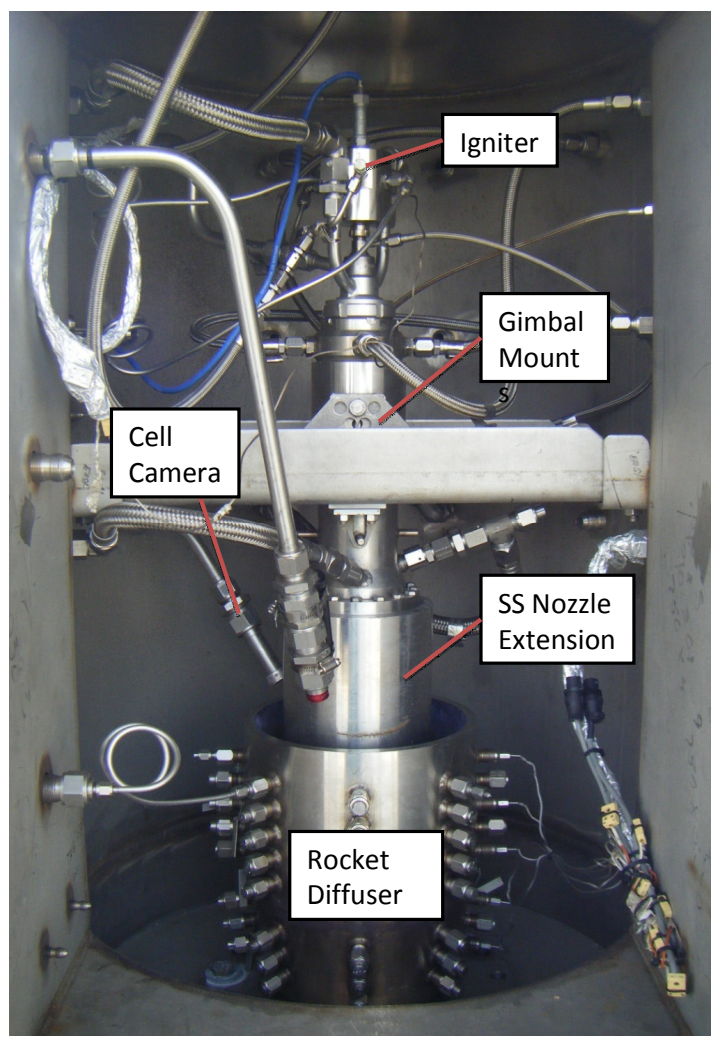

Figure 7. JSS Installed

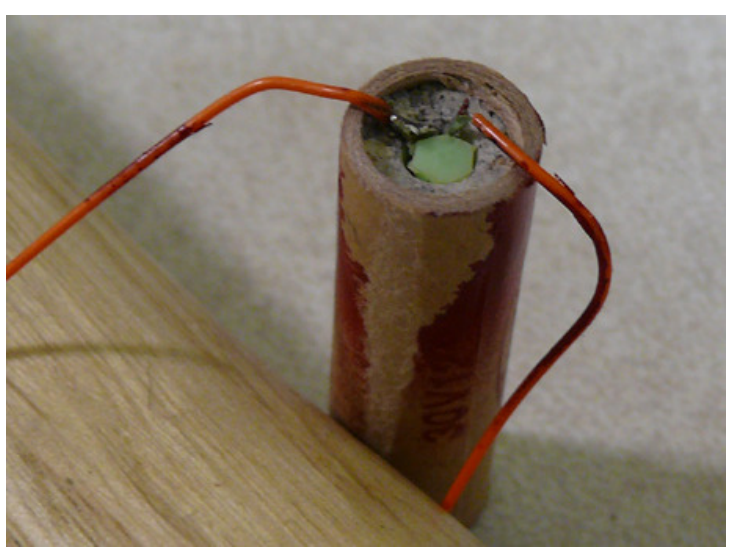

Figure 8. Estes Rocket Motor with Ignition Wires 


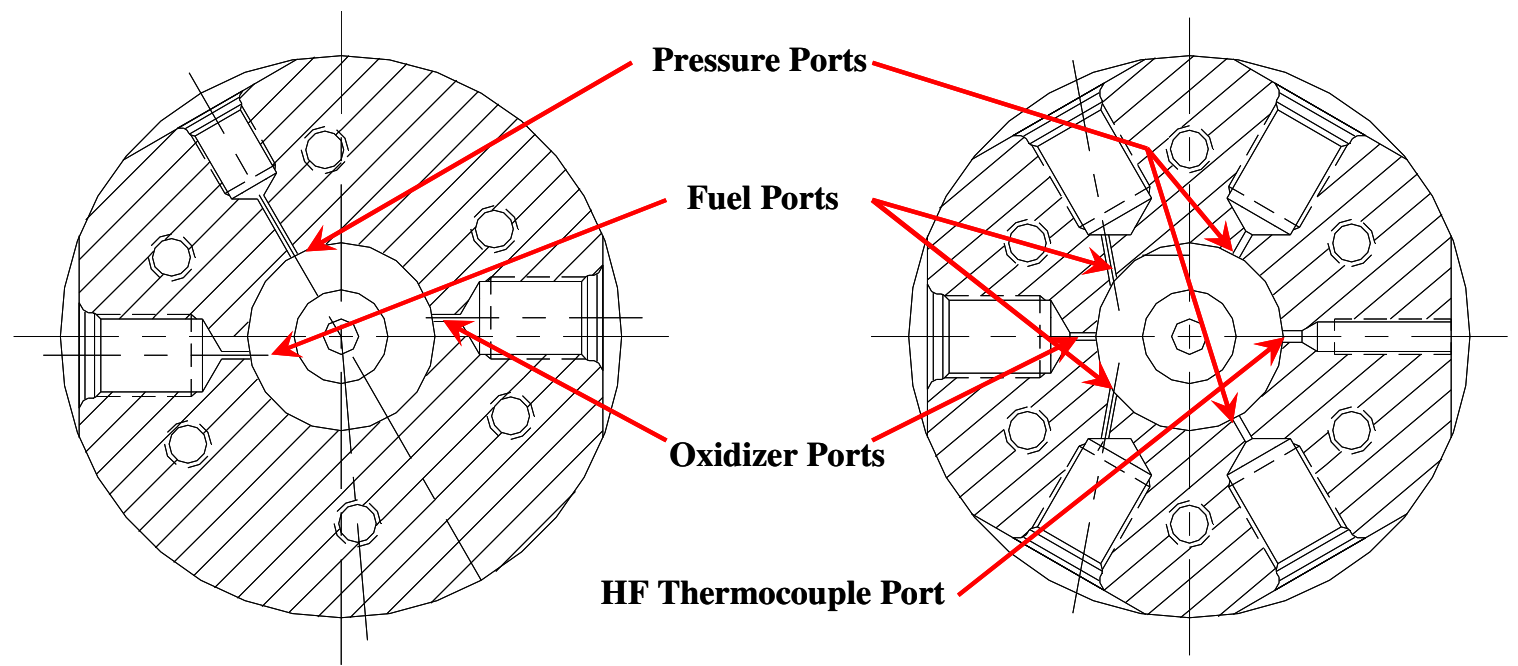

Figure 9. Original (Left) and Redesigned (Right) Igniter Inlet Port Arrangement

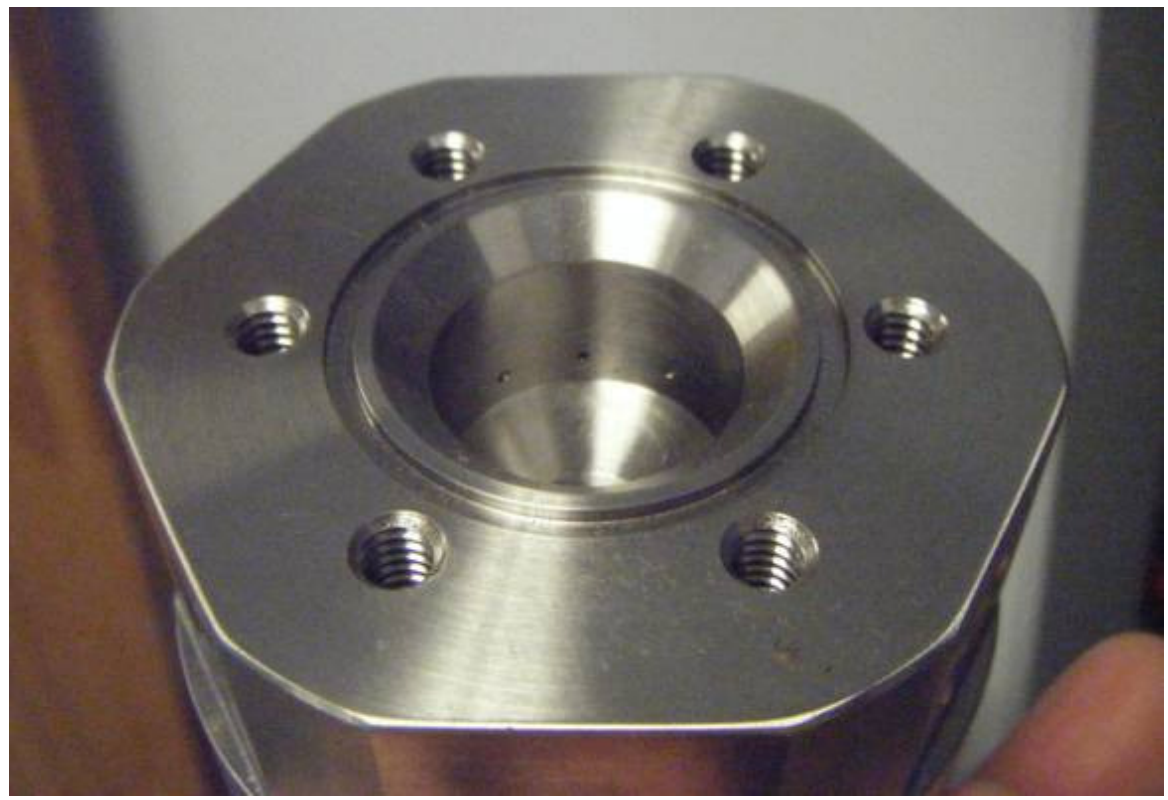

Figure 10. GOX/GH Spark Igniter Chamber

\section{Activation}

\section{A. J2-X Subscale Simulator (JSS)}

Activation of the JSS was performed at sea level conditions. Sea level conditions were attained by firing in the A3 subscale test cell with the test cell door open and without the nozzle extension installed. The nozzle area ratio without the nozzle extension was large enough that the truncated nozzle was overexpanded. The existing DTF heritage Estes rocket igniters were used. Initial firings were performed at low chamber pressures. After three successful firings, the chamber pressure and $\mathrm{O} / \mathrm{F}$ were tuned to match $\mathrm{J} 2-\mathrm{X} 80 \%$ RPL conditions. Three activation tests were run at $80 \%$ RPL. One activation hot fire test was run at target 100\% RPL conditions. Figure 11 shows the underexpanded plume entering the rocket diffuser during activation. 


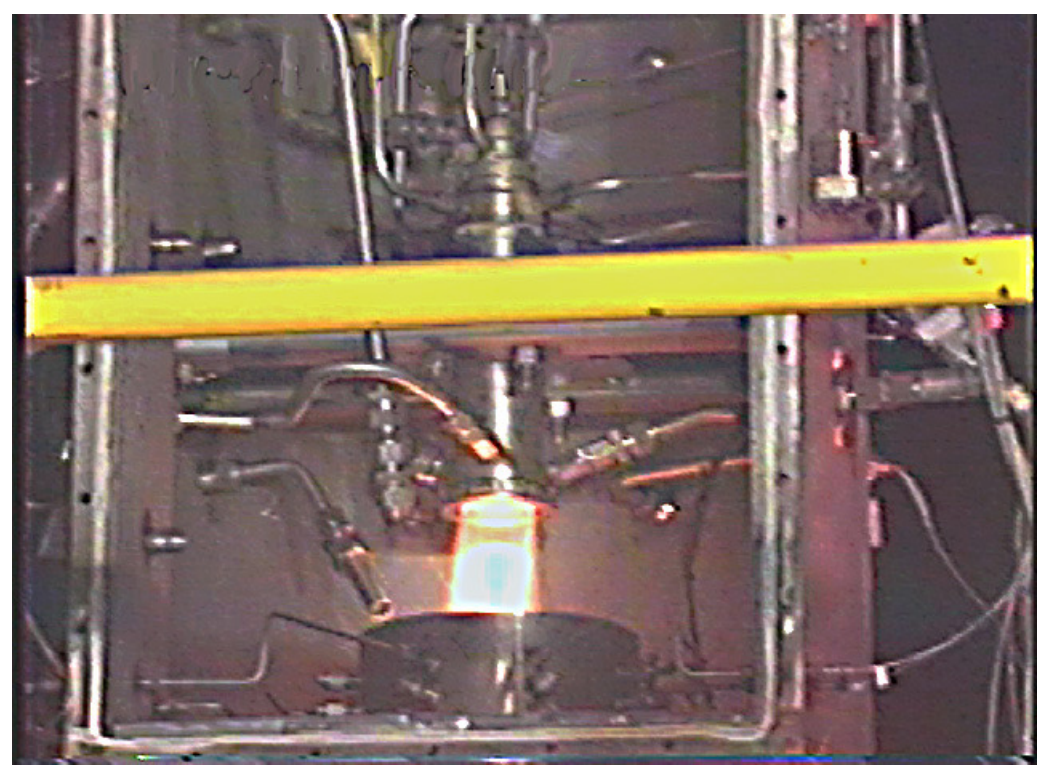

Figure 11. JSS Activation Hot Fire at Sea Level Conditions

One interesting side effect of activating the JSS at sea level was afterburning experience in the subscale diffuser exhaust train. The JSS plume entrained a large amount of free air when expanded into the rocket diffuser. The entrain air and hydrogen rich rocket exhaust readily burned in the diffusers. Figure 12 shows the large afterburning flame at the exit of the diffuser system.

An issue with the original chamber liner baffle was found during activation of the JSS. The original baffle design utilized steel wire to create the annular cooling water passage on the exterior surface of the liner. This passage was too small to pass the required JSS cooling water flow. The original design was modified to enlarge the annular cooling water passage and brass wire was used in lieu of steel to ease installation.

The brass wire baffle design has failed

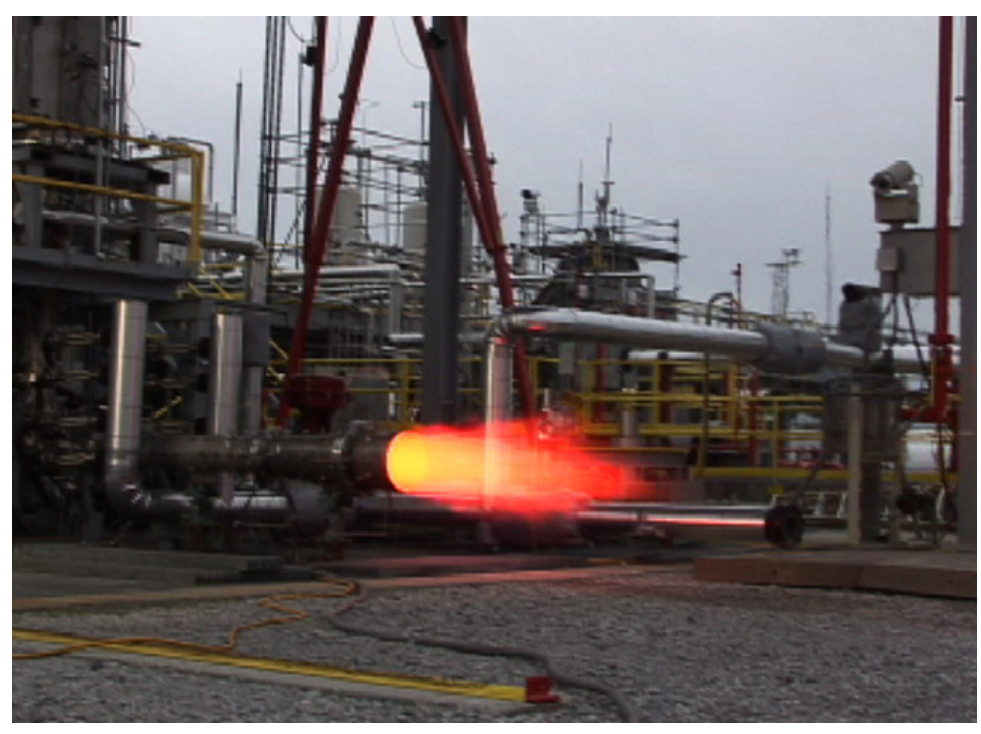

Figure 12. Afterburning During JSS Activation Testing twice during the test program. The brass wires were brazed to the brass baffle. Periodically these joints break under the extreme temperature gradients in the liner and the immense forces created by the high velocity cooling water flow. Twice when the joints have broken, a wire has dislodged and partially blocked the cooling water flow to the throat of the JSS nozzle. Hence, the JSS nozzle throat begins to erode. Figure 13 shows a JSS combustion chamber liner with an eroded throat. 


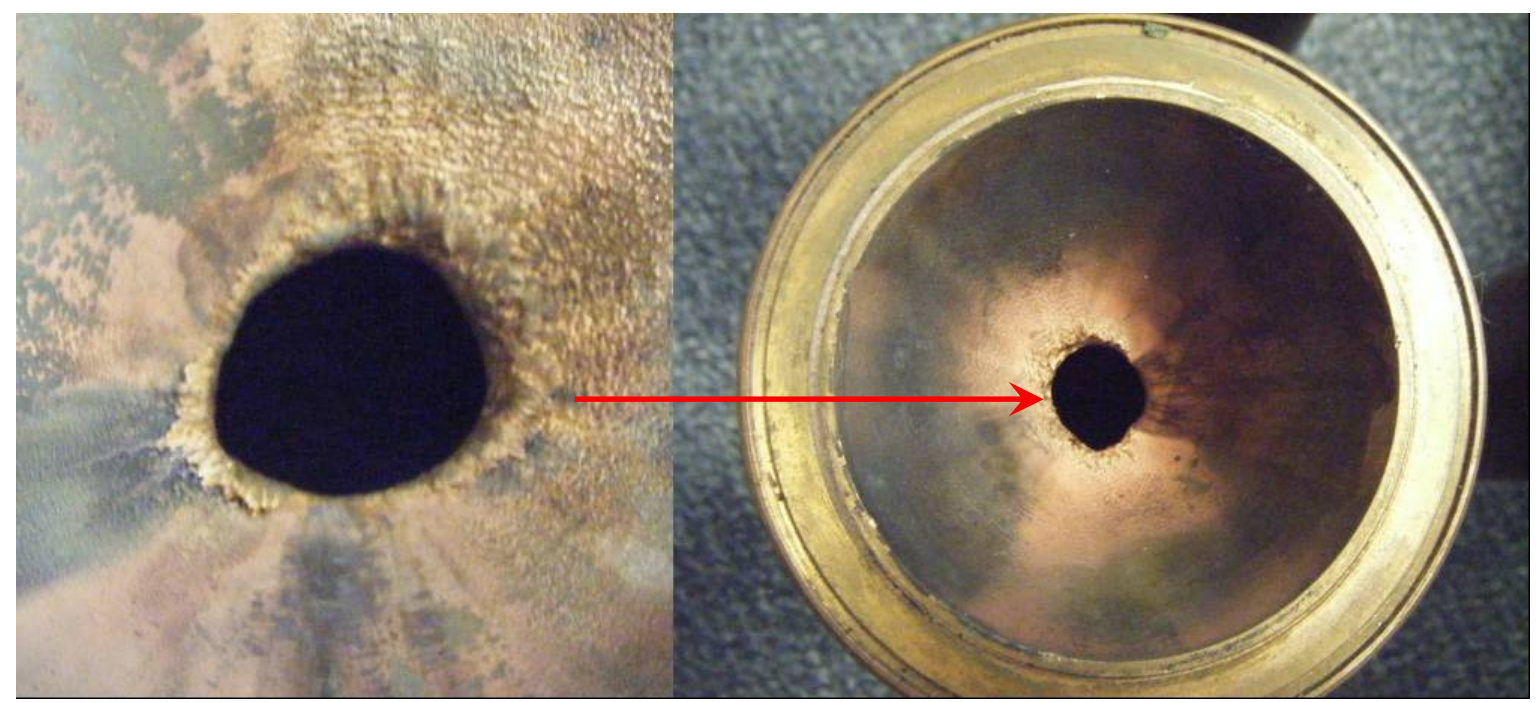

Figure 13. Eroded JSS Throat

\section{B. GOX/GH Igniter}

The GOX/GH spark igniter was design to operating at a low oxidizer-to-fuel ratio to keep the combustion temperature low enough to allow the use of an uncooled igniter body. The spark was generated using a AC transformer. The first spark igniter design was activated using an NGK platinum racing spark plug. First fuel flow was initiated and the spark plug energized. Then oxidizer flow was initiated. Three aspects of the design contributed to igniter failure: The ignition voltage was too low (arc was weak). The weak arc made it necessary to use a higher GOX flow rate than desired to obtain ignition. Secondly, the oxidizer and fuel were opposing in the chamber which limited gas mixing. Thirdly, the inlet ports were too close to the spark plug tip. When ignition did occur at the elevated oxidizer flow rate, the GOX jet passed directly in contact with the spark plug tip and ignited the plug tip. A photo of the failed hardware is shown in Figure 14.

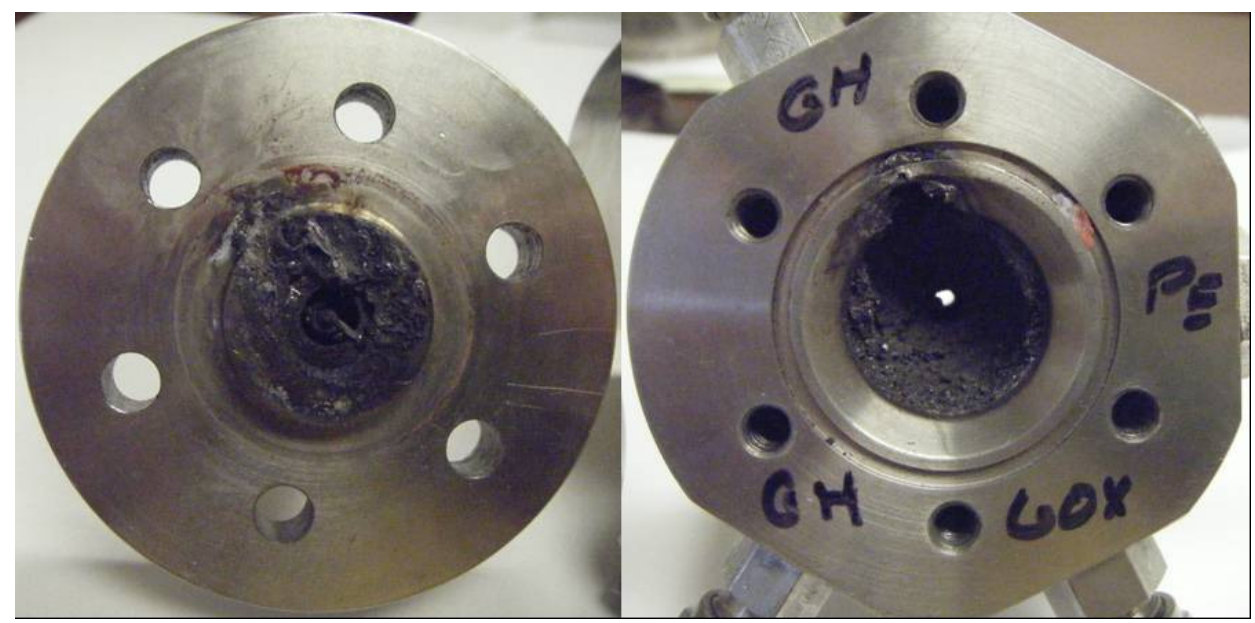

Figure 14. Failed Spark Igniter: Cap and Spark Plug (Left), Chamber (Right)

The spark igniter was subsequently redesigned to move the inlet ports away from the spark plug tip and with a triplet injection concept as outlined previously above. Also, the ignition electronics were replaced with a high performance automobile style high voltage ignition system using a 12 volt battery, control module, and a secondary ignition coil. The modification proved successful and the igniter has worked reliably since. 
The chamber pressure generated in the JSS is an order of magnitude higher than those experienced in internal combustion engines. Therefore, spark plug selection was a challenge as no spark plug manufacturer would guarantee operation of any common plug at these pressures. A vast array of candidate plugs were purchased and tested in the JSS. All would light the igniter without issue. However, the high chamber pressures produced in the JSS would typically break the insulator on the plug. Finally, a standard aircraft plug was found that can repeatedly withstand the chamber pressure in the JSS. The plug is a resistor type aircraft spark plug. It is modified for use in the GOX/GH spark igniter by replacing the resistor with a copper slug and the anodes are removed so the electrode arcs direct to the igniter chamber. The currently installed GOX/GH spark igniter with the modified aircraft plug has now fired the JSS over 90 times without issue.

\section{Conclusions}

A general description of the design and activation of the J2-X Subscale Simulator (JSS) has been given. The JSS and its spark ignition system have been successfully developed and have been an integral part of mitigating the technical risks associated with the A3 altitude simulating rocket test facility to be located at Stennis Space Center. The JSS has proven to be a workhorse test engine having been fired over 100 times since the inception of the A3 Subscale Diffuser Test (SDT) project and has been used continually since activation in January 2008.

\section{References}

${ }^{1}$ J. Ryan, C.A. Mulkey, N.G. Raines, G.P. Saunders, “An Overview of the A3 Subscale Diffuser Test Project”, AIAA-20084365 .

${ }^{2}$ G.P. Saunders, C.A. Mulkey, S.A. Taylor, "Design and Activation of a LOX/GH Chemical Steam Generator", AIAA-20095007.

${ }^{3}$ G.P. Saunders, “A3 Subscale Diffuser Test Article Design”, AIAA-2009-5010.

${ }^{4}$ G.P. Saunders, N.G. Raines, D.G. Varner, "Design, Activation, and Operation of the J2-X Subscale Simulator (JSS)", AIAA-2009-5098.

${ }^{5}$ G.P. Saunders, D.A. Wagner, “A3 Subscale Steam Ejector Performance Testing”, AIAA-2009-5100.

${ }^{6}$ G.P. Saunders, J. Yen, “A3 Subscale Rocket Hot Fire Testing”, AIAA-2009-5099.

${ }^{7}$ J. Yen, G.P. Saunders, D.A. Wagner, "Transient Heat Load Estimate for the A3 Supersonic Rocket Diffuser Using Surface Temperature Measurement", AIAA-2009-5012.

${ }^{8}$ J. Yen, G.P. Saunders, D.A. Wagner, "Error Analysis of the Surface Heat Flux Calculation for the A3 Supersonic Diffuser", AIAA-2009-5011.

${ }^{9}$ G.P. Saunders, D.G. Varner, J.B. Grover, "Description and Operation of the A3 Subscale Facility", AIAA-2009-5097.

${ }^{10}$ S. Elam, C. Sprader, “Test Summary Report for Test Program P2115,” NASA MSFC TR TD71-01-01, 2001. 